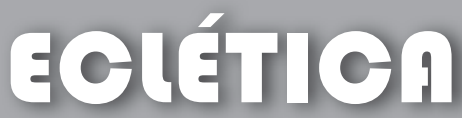 química
}

\section{EXTRAÇÃO DO CORANTE DA BETERRABA (BETA VULGARIS) PARA UTILIZAÇÃO COMO INDICADOR ÁCIDO-BASE}

\author{
Ariela Suzan Cuchinski ${ }^{l}$, Josiane Caetano ${ }^{2}$, Douglas C. Dragunski ${ }^{{ }^{*}}$ \\ ${ }^{1}$ Universidade Paranaense, Praça Mascarenhas de Moraes, 87502-210, Umuarama-PR-Brasil. \\ ${ }^{2}$ Departamento de Engenharias e Ciências Exatas, Universidade Estadual do Oeste do Paraná, UNIOESTE - PR, Toledo-PR \\ 85903-000, Brazil
}

\begin{abstract}
Resumo: No presente trabalho, foi investigado o comportamento do extrato aquoso e alcoólico da beterraba (Beta vulgaris) como um indicador ácido-base, tendo como objetivo principal despertar o interesse pelo uso dos indicadores naturais, como alternativa didática para transmissão dos conceitos de titulação, equilíbrio químico e a lei de Lambert-Beer. Para a realização dos experimentos foram utilizadas soluções padrão de ácido clorídrico $(\mathrm{HCl})$, ácido acético e hidróxido de sódio $(\mathrm{NaOH})$. Inicialmente foram feitos testes para avaliar a reversibilidade do sistema, e observou-se que a coloração passa de vermelho para amarela com adição de base e retorna para vermelho com adição do ácido, sendo possível sua utilização para explicação do equilíbrio químico. As análises de espectroscopia UV-vis mostraram que os espectros de absorção molecular na região do visível, apresentam diferentes característica, dando indícios que ocorreu modificação na estrutura do indicador em meio ácido e básico. Após as análises volumétricas constatou-se que os pontos de equivalência determinados com o indicador natural tiveram concordância com os obtidos pelo método potenciométrico. Além disso, os extratos aquosos e alcoólicos da beterraba apresentam potencial didático para a explicação da lei de Lambert-Beer, sendo que no meio ácido houve uma melhor correlação comparado com o meio básico.
\end{abstract}

Palavras-chave: beterraba, titulação, indicador natural.

\section{Introdução}

Inúmeras espécies de plantas, flores e frutas possuem substâncias coloridas em sua seiva que mudam de cor conforme o pH do meio em que estão inseridas, sugerindo que tais espécies podem atuar como indicadores ácido-base. Estes indicadores naturais estão se revelando como um providencial recurso didático utilizado em algumas regiões do país [1].

Os indicadores são substâncias capazes de mudar de cor dependendo das características físicoquímicas da solução na qual estão contidas. Podem ser classificados de acordo com o mecanismo de mudança de cor ou os tipos de titulação nos quais são aplicados. Os indicadores ácido-base, ou indicadores de $\mathrm{pH}$, são substâncias orgânicas fracamente ácidas (indicadores ácidos) ou fracamente básicas (indicadores básicos) que apresentam cores diferentes para as suas formas protonadas e desprotonadas. A mudança de coloração ocorre numa estreita, porém, bem definida faixa de $\mathrm{pH}$ [2].

Os ácidos e as bases estão entre os compostos mais comuns, sendo que muitos são substâncias industriais e domésticas, e alguns deles componentes dos líquidos biológicos [3]. Também podem ser usados na química para determinar as concentrações de vários componentes de uma amostra. Isso ocorre quando são realizadas titulações em que o titulante e o titulado são bases ou ácidos reagindo estequiometricamente. A utilização de um método visual de mudança de coloração com o auxílio de indicadores de $\mathrm{pH}$, é uma forma para identificar a equivalência entre os ácidos de 
bases. Assim, à substância é adicionada á solução a ser titulada até que ocorra uma alteração de coloração, indicando o ponto final. Outra maneira de se realizar esta titulação é através de um pHmetro, em que é possível observar a variação de algumas unidades no $\mathrm{pH}$ da solução $[4,5,6]$.

Uma alternativa para ensinar a titulação em aulas práticas é a utilização de corantes naturais, os quais possuem a propriedade de mudar de coloração quando se varia o $\mathrm{pH}$. A beterraba é um destes indicadores naturais pertencendo à família Chenopodiaceae, na qual a parte comestível é a raiz tuberosa. Esta hortaliça tem coloração vermelho-arroxeada devido à presença dos pigmentos betalaínas. As betalaínas são compostos semelhantes às antocianinas e flavonóides, sendo pigmentos hidrossolúveis e são divididas em duas classes: betacianina (responsável pela coloração avermelhada) e betaxantina (responsável pela coloração amarelada), caracterizando a coloração típica das raízes de beterraba [7].

$\mathrm{Na}$ beterraba fica evidenciada a presença de um pigmento vermelho com características polares, a substância betanina, que corresponde a entre $75 \%$ e $95 \%$ dos pigmentos. As betalaínas são estáveis em pH 4 e 5; e razoavelmente estáveis em pH 5 a 7 e instáveis em presença de luz e ar, além destes fatores a atividade de água e o oxigênio afetam a estabilidade dos pigmentos[8].

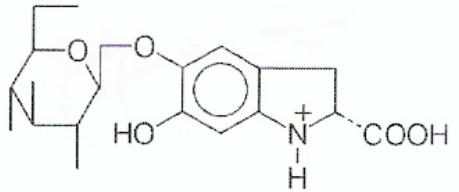

ciclodopa-5-o-glicosídio<smiles>O=C/C=C1/C=C(C(=O)O)NC(C(=O)O)C1</smiles>

ácido betâmiıo<smiles>CCOC(=O)C1CC(=CC=[N+]2c3cc(O)c(OCOC4OC(CC)C5CC4C5C)cc3CC2C(=O)O)C=C(C(=O)O)N1</smiles><smiles>CCC1OC2CC(C1C)C(C)C2COc1cc2c(cc1O)[N+](=CN=C1C=C(C(=O)O)NC(C(=O)O)C1)C(C(=O)O)C2</smiles><smiles>CCC1OC2CC(CC2C)C1OCC(C)C</smiles>

Figura 1. Conversão da betanina em função do pH do meio. 
Os extratos da beterraba apresentam diferentes colorações quando estão em meio ácido ou básico. O comportamento observado é justificado pela isomerização da betanina em função do $\mathrm{pH}$ do meio, conforme pode-se observar na figura 1 [8].

Assim, este trabalho teve como objetivo despertar o interesse pelo uso dos indicadores naturais (extratos de beterraba), como alternativa didática para transmissão dos conceitos de titulação, equilíbrio químico e aplicação da lei de Lambert-Beer, devido a sua fácil obtenção e baixo custo para o ensino, proporcionando sua utilização em qualquer escola.

\section{Material e Métodos}

\subsection{Obtenção do extrato}

\subsubsection{Extrato aquoso}

A espécie utilizada para obtenção dos extratos da beterraba foi a Beta vulgaris, em que foram usados aproximadamente $50 \mathrm{~g}$ de beterraba in natura, previamente descascada e cortada. Posteriormente, adicionou-se $150 \mathrm{~mL}$ de água destilada, aqueceu-se a solução à fervura, até que a água reduzisse a metade do volume inicial. O tempo da extração foi de aproximadamente 45 minutos, esperou-se a solução esfriar onde então se filtrou, sendo posteriormente armazenado em frasco escuro, em congelador doméstico [9].

\subsubsection{Extrato alcoólico}

Para a obtenção do extrato alcoólico foram utilizados $50 \mathrm{~g}$ de beterraba in natura, previamente descascada e cortada em pequenos pedaços e utilizou-se como solvente $100 \mathrm{~mL}$ de etanol 99,5\%; o tempo estabelecido para a extração foi de 48 horas. O béquer foi envolto por papel alumínio e mantido em temperatura ambiente, após este período filtrou-se a solução e levou o filtrado à evaporação em rota evaporador à temperatura de $49^{\circ} \mathrm{C}$, até obtenção de volume constante, o extrato foi armazenado em frasco escuro, em congelador doméstico [10].

\subsection{Reagente e soluções}

As soluções foram preparadas com água destilada. Todas as operações foram realizadas em sala climatizada a $(25 \pm 1){ }^{\circ} \mathrm{C}$, onde se encontram instalados os equipamentos de medida. Tanto as soluções dos ácidos clorídrico e acético quanto às soluções de hidróxido de sódio foram preparadas em concentrações de $0,1 \mathrm{~mol} \mathrm{~L}^{-1}$, segundo procedimento descrito em livros-texto de química analítica experimental, posteriormente padronizadas [11]. Estas soluções foram utilizadas nas titulações ácido-base.

\subsection{Equipamentos}

$\mathrm{pH}$ - metro com eletrodo combinado de vidro: TECNAL Tec-2;

Rota - Evaporador: TECNAL Te - 210, acoplado a uma bomba de vácuo TECNAL Te-058;

Espectrofotômetro: Analyser $800 \mathrm{M}$;

Agitador: Fieston Mod. 752 A;

\subsection{Análise Volumétrica}

As análises volumétricas foram realizadas utilizando as soluções padronizadas de ácidos clorídrico e acético (titulados) e hidróxido de sódio (titulante). O extrato de beterraba foi utilizado como indicador do ponto final. Foram usadas pipetas de $20 \mathrm{~mL}$ e buretas de $50 \mathrm{~mL}$, calibradas previamente. Para comparação dos valores obtidos, fez-se a mesma titulação usando o eletrodo de vidro combinado, em que o valor do ponto de equivalência foi determinado através da primeira derivada.

\subsection{Lei de Lambert-Beer}

Espectros de absorção na região do ultravioleta e do visível foram obtidos em diferentes valores de $\mathrm{pH}$, para determinação dos comprimentos de onda dos máximos de absorção, bem como para demonstração da alteração destes espectros em função da acidez do meio.

Para verificação da lei de Lambert-Beer foram utilizadas alíquotas do extrato aquoso e alcoólico, 0,$2 ; 0,4 ; 0,6 ; 0,8$; e $1,0 \mathrm{~mL}$, respectivamente as quais foram diluídas com soluções de $\mathrm{HCl}$ e $\mathrm{NaOH}$, obtendo-se um volume final de $5 \mathrm{~mL}$. As absorbâncias foram medidas em função da diluição.

\section{Resultados e discussão}

\subsection{Reversibilidade do equilibrio e mudança de cor em função do $\mathrm{pH}$}

Inicialmente os extratos foram colocados em diferentes $\mathrm{pH}$ (1 à 12) para avaliar a alteração de coloração. Nas Figuras $2 \mathrm{a}$ e $2 \mathrm{~b}$, pode-se observar que tanto o extrato aquoso como o alcoólico apresentaram coloração avermelhada quando colocados em meio ácido, apresentando alteração de coloração com o aumento do $\mathrm{pH}$. Na faixa de $\mathrm{pH}$ entre 1 e 9,5 a coloração permaneceu a mesma (vermelha), entretanto ocorreu uma alteração na coloração para amarelo próximo do $\mathrm{pH} 12$. Assim este indicador natural poderia ser utilizado para visualizar diferenças entre pH abaixo de 9,5 (vermelho) e acima 12,1 (amarelo). Foram também realizados testes para avaliar a reversibilidade deste sistema. Notou-se que após a 
(a)

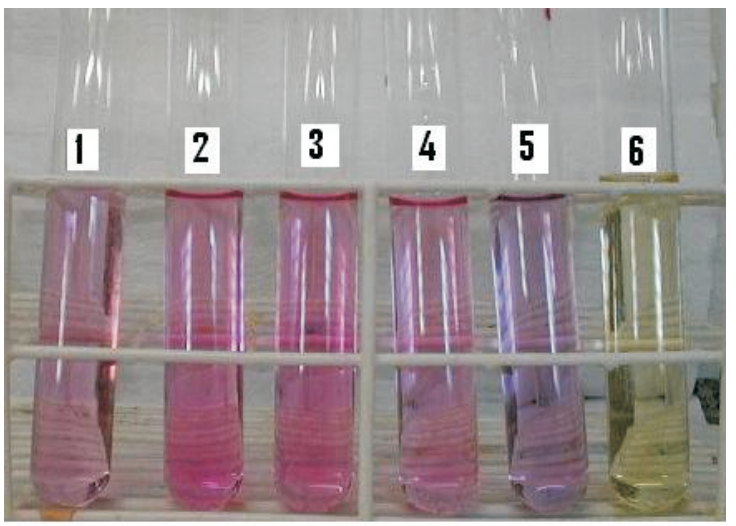

(b)

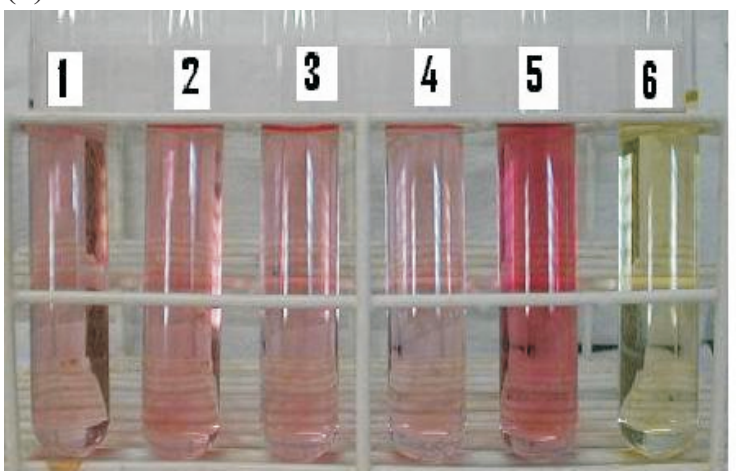

Figura 2. (a) Escala de $\mathrm{pH}$ para o extrato aquoso: tubo $1 \mathrm{pH}$ 1,2; tubo $2 \mathrm{pH} \mathrm{3,1;} \mathrm{tubo} 3 \mathrm{pH}$ 5,5; tubo $4 \mathrm{pH} 9,5$; tubo $5 \mathrm{pH}$ 10,8 e tubo $6 \mathrm{pH}$ 12,1. (b) Escala de $\mathrm{pH}$ para o extrato alcoólico: tubo $1 \mathrm{pH} 1,2$; tubo $2 \mathrm{pH} 3,1$; tubo 3 pH 5,5; tubo 4 pH 9,5; tubo 5 pH 10,8 e tubo 6 pH 12,1.

adição de ácido (quando a coloração encontrava-se amarela, $\mathrm{pH}>12$ ), ocorreu o retorno da coloração vermelha, indicando que a beterraba poderá ser utilizada em estudos para a demonstração do equilíbrio químico, corroborando com estudos realizados pelo GEPEQ [12].

\subsection{Comparação entre métodos}

Para avaliar a viabilidade na utilização destes indicadores, foram realizadas titulações ácido-base e comparadas com a tradicional técnica potenciométrica utilizando o eletrodo de vidro.

As medidas foram realizadas em triplicata usando o ácido clorídrico e o acético como titulados e o hidróxido de sódio como titulante. Para as medidas potenciométricas os volumes de equivalência foram obtidos utilizando a primeira derivada (figuras $3 a$ e $3 b$ ).
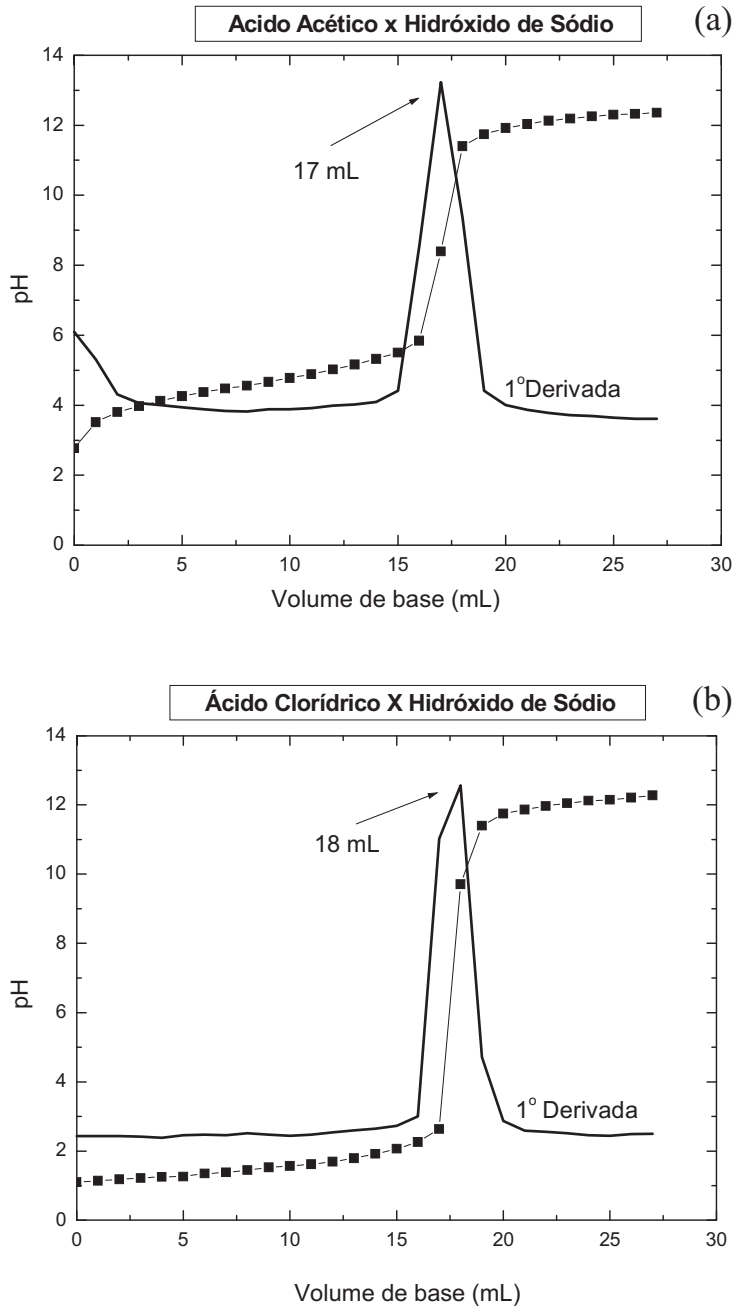

Figura 3. (a) Titulação potenciométrica de ácido acético com hidróxido de sódio; (b) Titulação potenciométrica de ácido clorídrico com hidróxido de sódio.

Comparando os resultados da titulação potenciométrica com a titulação volumétrica (tabela 1), pode-se notar que os mesmos estão próximos, indicando que este extrato poderá ser utilizado como indicador ácido-base em titulações, sendo que o valor do erro comparando o método potenciométrico com o visual foi em torno de $2 \%$, este erro é observado geralmente nas titulações. Nota-se que para o ácido fraco o erro foi mais pronunciado $(6,1 \%)$, corroborando com o apresentado por Bobbio [13], pois o extrato em meio básico pode sofre alguns modificações estruturais, dificultando a visualização do ponto de viragem, proporcionando assim um maior erro. 
Tabela 1. Comparação entre os resultados de detecção dos pontos finais em titulação ácido - base, utilizando extrato aquoso e alcoólico como indicador visual e com eletrodo de vidro.

\begin{tabular}{c|l|c|c|c}
\hline \multirow{2}{*}{ Sistema } & & \multicolumn{2}{|c}{ Volume médio de equivalência* $(\mathrm{mL})$} \\
\hline \multirow{2}{*}{$\mathrm{HCl} / \mathrm{NaOH}$} & Potenciométrico & Visual & Erro (\%) & \\
\hline & Extrato aquoso & 18,0 & 17,6 & 2,2 \\
\cline { 2 - 5 } & Extrato alcoólico & 18,0 & 17,5 & 2,7 \\
\hline \multirow{2}{*}{ Ac. Acético/ $\mathrm{NaOH}$} & Extrato aquoso & 17,0 & 17,7 & 4,1 \\
\cline { 2 - 5 } & Extrato alcoólico & 17,0 & 18,0 & 6,1 \\
\hline
\end{tabular}

* Média de 3 determinações. Condições: volume de ácido titulado $=20 \mathrm{~mL}$. Todos os reagentes utilizados em concentrações de $0,1 \mathrm{~mol} \mathrm{~L}^{-1}$. Titulante adicionado a partir de uma bureta de $50,0 \mathrm{~mL}$

\subsection{Espectros de absorção molecular}

As medidas espectroscópicas mostraram alterações nas bandas espectrais, dando indícios de que as estruturas das moléculas sofreram modificações em diferentes pH $(3,1$ e 12,1), como pode ser visto nas figuras $4 \mathrm{a}$ e $4 \mathrm{~b}$.

O comportamento do extrato aquoso e alcoólico da beterraba, tanto em meio ácido quanto em meio básico, demonstra a modificação de coloração associada à forma dos espectros, ou seja, dos máximos de absorção, como mostrados nas figuras 4a e 4b [14]. Em meio ácido, predomina uma coloração vermelha ( $\mathrm{pH}$ abaixo de 5,0$)$, com $\lambda_{\text {máx. }}$ (comprimento de onda máximo) em $540 \mathrm{~nm}$ para o extrato aquoso e $545 \mathrm{~nm}$ para o extrato alcoólico.

(a)

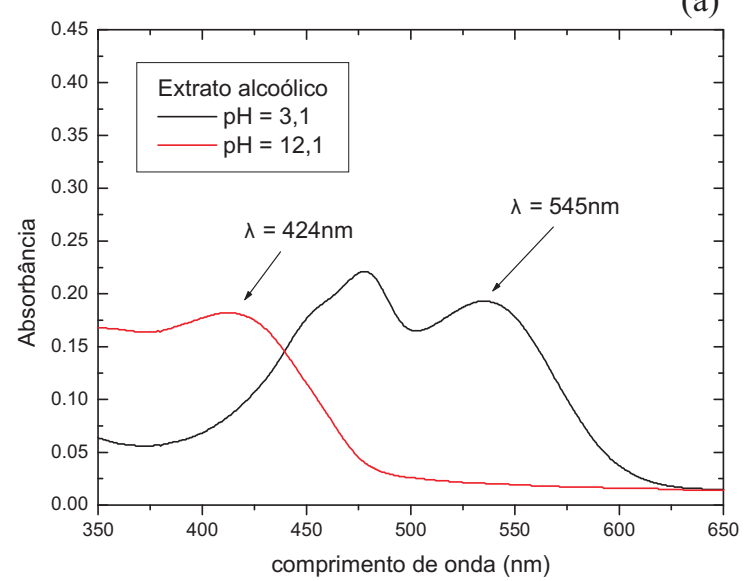

Utilizou-se este valor de absorção, devido a esta banda estar mais distante da forma básica, assim pode-se visualizar melhor os resultados. No meio básico $(\mathrm{pH}$ acima de 12,0), apresenta-se uma coloração amarela, com intensificação da banda em $418 \mathrm{~nm}$ para o extrato aquoso e $424 \mathrm{~nm}$ para o extrato alcoólico. A mudança de coloração geralmente é atribuída à variação estrutural dos corantes presentes no extrato, neste caso principalmente as betalaínas. Esses resultados corroboram com os obtidos visualmente.

\subsection{Verificação da lei de Lambert-Beer}

A relação que existe entre a absorbância de uma solução e a quantidade de espécie absorvente, em certo comprimento de onda, é dada pela expressão [15]:

Figura 4. (a) Espectros de absorção molecular do extrato alcoólico em meios ácido e básico. (b) Espectros de absorção molecular do extrato aquoso em meios ácido e básico. 
$\mathrm{A}_{\lambda}=\mathrm{a}_{\lambda} \mathrm{bc}$

onde

$\mathrm{A}_{\lambda}=$ absorbância no comprimento de onda $\lambda$.

$\mathrm{a}_{\lambda}=$ coeficiente de absortividade no comprimento

de onda $\lambda$.

$\mathrm{b}=$ caminho óptico.

$\mathrm{c}=$ concentração da espécie absorvente.

A lei de Lambert-Beer propõe uma dependência linear entre a absorbância e a concentração das espécies presentes em uma solução. Assim, observouse o comportamento dos extratos alcoólico e aquoso da beterraba, em relação a esta lei. Os resultados obtidos estão apresentados nas figuras 5a e 5b.

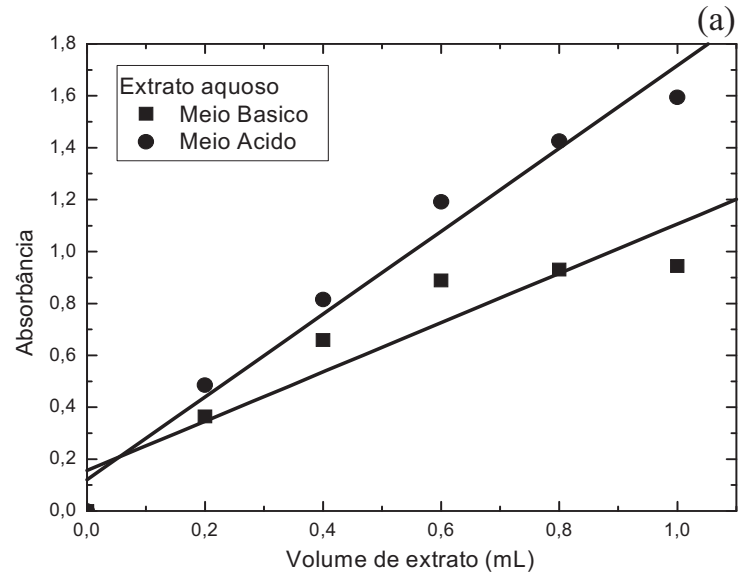

(b)

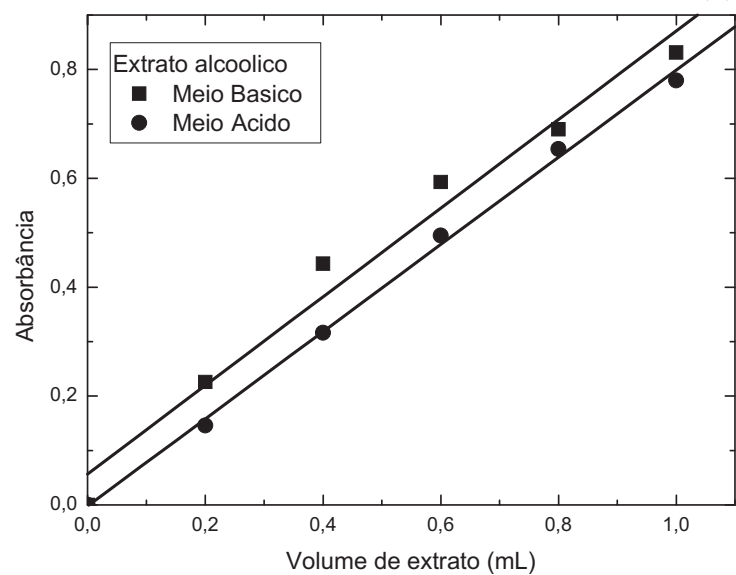

Figura 5. (a) Valores de absorbância em função da concentração de extrato, $\lambda_{\text {máx. }}$ de $540 \mathrm{~nm}$ para o meio ácido e $\lambda_{\text {maxx }}$ de 418 para o meio básico. (b) Valores de absorbância em função da concentração de extrato, $\lambda_{\text {máx. }}$ de $545 \mathrm{~nm}$ para o meio ácido e $\lambda_{\text {maxx. }} 424$ para o meio básico.
Constatou-se que em meio ácido, tanto para o extrato aquoso quanto alcoólico, os pontos estão mais próximos da reta, ou seja, o valor do coeficiente linear está mais próximo de 1 , como mostrado nas figuras $5 \mathrm{a}$ e $5 \mathrm{~b}$ e na tabela 2. Entretanto, para o meio básico não se observa o mesmo comportamento, ou seja, os pontos não estão próximos da reta e os valores do coeficiente são diferentes de 1. Estes desvios podem ser atribuídos à instabilidade do extrato em meio básico como mostrado por Bobbio [13].

Tabela 2. Resultados do comportamento do extrato aquoso e alcoólico em relação à lei de Lambert-Beer.

\begin{tabular}{c|c|c|c|c|c}
\hline \multicolumn{3}{c|}{ Forma ácida } & \multicolumn{3}{c}{ Forma básica } \\
\hline$\lambda / \mathrm{nm}$ & Extrato & $\mathrm{r}$ & $\lambda / \mathrm{nm}$ & Extrato & $\mathrm{r}$ \\
\hline 545 & alcoólico & 0,998 & 424 & alcoólico & 0,988 \\
\hline 540 & aquoso & 0,987 & 418 & aquoso & 0,934
\end{tabular}

r-coeficiente de correlação

Através dos dados apresentados observa-se que o extrato alcoólico obteve um melhor resultado em relação à lei de Lambert-Beer para o meio ácido e básico. No entanto, o extrato aquoso apresentou resultados satisfatórios para o meio ácido.

\section{Conclusão}

Os resultados para os extratos de beterraba mostraram-se promissores para sua utilização como indicadores de $\mathrm{pH}$ em titulações ácido-base, pois a mudança de coloração foi percebida facilmente no ponto de viragem, além dos volumes de equivalência estarem próximos aos obtidos com o eletrodo de vidro (potenciométrico). Podem também ser aplicados para a explicação de equilíbrio químico, por ter apresentado boa reversibilidade da cor em diferentes $\mathrm{pH}$.

Os extratos apresentaram uma boa concordância com a lei de Lambert-Beer, tendo um destaque para o extrato alcoólico, o qual apresentou excelente correlação, tanto em meio ácido quanto básico. Portanto, estes extratos podem ser uma alternativa simples e de baixo custo para explicar diversos conteúdos nas aulas de química, tornando o aprendizado mais interessante. 
Ariela Suzan Cuchinski, Josiane Caetano, Douglas C. Dragunski. Extraction of the dye of beet (Beta vulgaris) for use as indicated in acid-base.

\begin{abstract}
In this study, we investigated the behavior of aqueous and alcoholic extract of sugar beet (Beta vulgaris) as an acid-base indicator, having as main objective the awakening interest in the use of natural indicators as an alternative to teaching of concepts of titration, equilibrium chemical and the law of LambertBeer. For the experiments we used standard solutions of hydrochloric acid $(\mathrm{HCl})$, acetic acid and sodium hydroxide $(\mathrm{NaOH})$. Initially tests were performed to evaluate and reversibility of the system, and it was observed that the color changes from red to yellow with the addition of base and returns to red with acid addition, so can be used to explain the chemical equilibrium. The analysis of UV-vis spectra showed that the molecular absorption in the visible region, have different characteristics, giving evidence that was altered structure of the indicator in acidic and basic medium. After the titration was found that the points of equivalence with the natural indicator showed concordance with those obtained by potentiometric method. Furthermore, the aqueous and alcoholic extract of beet has a good correlation for Beer-Lambert law, being that the acidic medium presented a better correlation compared with basic.
\end{abstract}

Keywords: beet, titration, natural indicator.

\section{Referências}

[1] C. A. I. Mazali, F. Ferraz, I. C. Voegel, A. B. Sá, Revista Científica do IMAPES (2006) 13.

[2] D. B. L. Terci, A. V. Rossi, Quím. Nova 25 (4) (2002) 684.

[3] T. L. Brow, E. H. Lemay Junior, B. E. Bursten, Química ciência central, 7 ed., Rio de Janeiro: LTC, 1999, cap. 4.

[4] O. A. Ohlweiler, Química analítica quantitativa, LTC, Rio de Janeiro, 3 ed., 1982, v.1, cap. 3.

[5] J. B. Russell, L. Sanioto, Química geral, São Paulo: Nacional, 1981, cap.15.

[6] J. Terra, A. V. Rossi, Quím. Nova 28 (1) (2005) 157.

[7] M. C. D. Vitti, R. A. Kluge, L. K. Yamamotto, A. P. Jacomino, Horticultura Brasileira 21 (4) (2003) 623.

[8] M. V. Dias, P.I.C. Guimarães, F. Merçon, Química Nova na Escola, 17 (2003) 27.
[9] M. H. F. B. Soares, P. A. Antunes, E. T. G. Cavalheiro, Quím. Nova, 24 (3) (2001) 408.

[10] L.A. Ramos, K. O. Lupetti, E. T. G. Cavalheiro, O. Fatibello-Filho, Eclet. Quim. 25 (2000) 229.

[11] T. Morita, Manual de soluções, reagentes e solventes. Padronização - Preparação - Purificação, Edgard Blucher, São Paulo, 2 ed., 1981, cap. 1-3.

[12] GEPEQ, Química Nova na Escola, (1) (1995) 32.

[13] P. A. Bobbio, F. O. Bobbio, Química de processamento de alimentos, Varela, São Paulo, $3^{\text {a }}$ ed., 2001.

[14] M. H. T. Pinheiro, W.N. Lima, Eclet. Quim. 24 (1999) 9.

[15] A. B. Couto, L. A. Ramos, E. T. G. Cavalheiro, Quím. Nova, 21 (2) (1998) 221. 
